epl draft

\title{
Nitride quantum light sources
}

\author{
T. ZHU AND R. A. OLIVER \\ received and accepted dates provided by the publisher \\ other relevant dates provided by the publisher \\ PACS 81.07.Ta - Quantum dots \\ PACS 81.05.Ea - III-V semiconductors \\ PACS 42.50.Dv - Antibunched photon states; nonclassical states
}

Department of Materials Science and Metallurgy, University of Cambridge, 27 Charles Babbage Road Cambridge CB3 OFS

\begin{abstract}
Prototype nitride quantum light sources, particularly single photon emitters, have been successfully demonstrated, despite the challenges inherent in this complex materials system. The large band offsets available between different nitride alloys have allowed device operation at easily accessible temperatures. A wide range of approaches have been explored: not only self-assembled quantum dot growth but also lithographic methods for site-controlled nanostructure formation. All these approaches face common challenges, particularly strong background signals which contaminate the single photon stream and excessive spectral diffusion of the quantum dot emission wavelength. If these challenges can be successfully overcome, then ongoing rapid progress in the conventional III-V semiconductors provides a roadmap for future progress in the nitrides.
\end{abstract}

Introduction - A quantum light source is a device which generates either individual photons or pairs in a regulated stream $^{1}$. Nitride-based light emitting diodes (LEDs) and laser diodes (LDs) which exploit quantum wells (QWs) or quantum dots (QDs) in the active region have been enormously successful; the Nobel Prize in Physics was awarded to the developers of the blue LED. However, these are not quantum light sources within our definition: for LEDs and LDs the number of photons emitted in a given time interval follows a statistical distribution. As nitride technology becomes more mature the impetus to pursue true nitride quantum light sources increases, targeting applications in quantum key distribution $(\mathrm{QKD})^{2}$ and linear optic quantum computation $(\mathrm{LOQC})^{3}$, with a particular current emphasis on single photon sources (SPSs).

Within the many different approaches to the development of SPSs ${ }^{4}$, we concentrate here on semiconductor QDs. Whilst our focus is on the III-nitride semiconductors, achievements in the more mature III-arsenides provide inspiration for future developments in the nitrides. The first optically-pumped QD single photon source was produced using InAs QDs grown by Stanski-Krastanov (SK) growth on $\mathrm{GaAs}^{5}$ in 2000, and a single photon emitting LED, a more practical solution for QKD, was developed as early as $2002^{6}$. Exploitation of $\mathrm{InAs} / \mathrm{InP}^{7}$ QDs has allowed single photon emission at 1.54 $\mu \mathrm{m}$, close to the ideal window for QKD using optical fibres.

For LOQC, photon indistinguishability is a key requirement, and has been demonstrated for the emission of InAs/GaAs QDs $^{8}$. Optically ${ }^{9}$ and electrically ${ }^{10}$ pumped sources of entangled photon pairs have also been demonstrated. Nanoscale device processing in the arsenides is well-established, enabling not only the integration of arsenide QDs into micropillar ${ }^{11}$, microdisk ${ }^{12}$ and photonic crystal defect ${ }^{13}$ cavities to spatially direct the photons and enhance emission rates, but also progress towards semiconductor integrated quantum optical circuits with components such as beam splitters being integrated with quantum emitters ${ }^{14}$.

Given this impressive set of achievements in the conventional III-Vs, one must justify pursuing SPSs in the nitrides, which are highly defected and difficult to process. One motivation for developing nitride SPSs is to broaden the available range of wavelengths. The conventional III-Vs have been very successful in the near infra-red, and using $\mathrm{InP} / \mathrm{GaInP}^{15}$ wavelengths as short as $680 \mathrm{~nm}$ are accessible. Other materials allow shorter wavelengths to be reached; e.g. $520 \mathrm{~nm}$ using CdSe QDs ${ }^{16}$. However, until the advent of the III-nitrides, blue and UV QD SPSs were unattainable. These wavelengths are desirable for potential applications of SPSs in QKD via satellite-to-satellite communication. Pragmatically, blue and green SPSs would be convenient in the laboratory due to the wide availability of ultra-fast detectors which require only Peltier cooling in this spectral region.

The nitrides also have advantageous fundamental physical properties: The large available band offsets between different nitride alloys can provide a high barrier to carrier escape from a QD, improving the temperature stability of an SPS. Furthermore, these non-centrosymmetric materials have very large piezo-electric constants resulting in substantial internal electric fields in strained QDs grown on the polar c-plane,

${ }^{(a)}$ E-mail: rao28@cam.ac.uk 


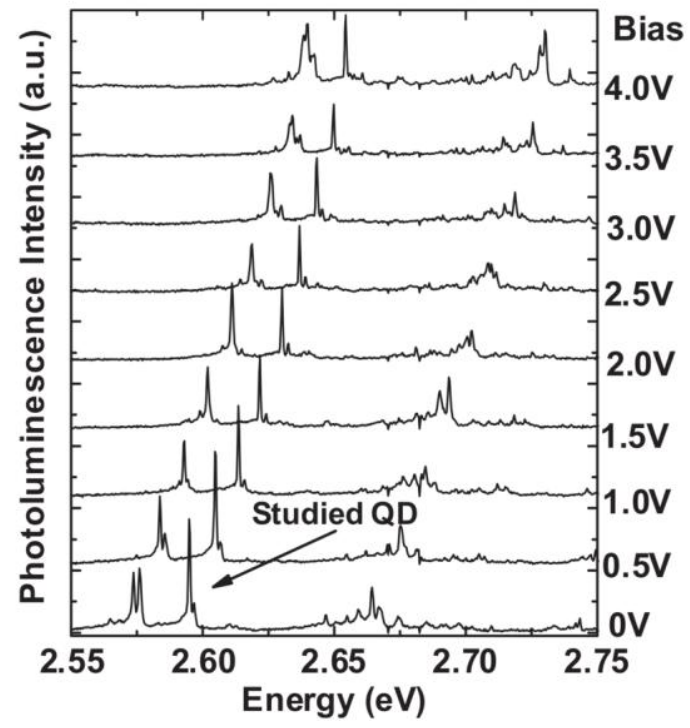

Fig. 1: Micro-photoluminescence ( $\mu \mathrm{PL})$ from InGaN QDs in a reverse biased diode at $4.2 \mathrm{~K}$. The QD emission shifts by $\sim 60$ $\mathrm{meV}$ on application of $4 \mathrm{~V}$. Figure reproduced with permission from reference [17] (C) 2007, American Physical Society.

which may be manipulated by an external electric field, tuning the QD emission energy ${ }^{17}$ by over $60 \mathrm{meV}$ (Fig. 1). Recently,highly polarised emission has been achieved from nitride QDs ${ }^{18}$ grown on non-polar surfaces, originating from valence band mixing effects, which has potential advantages for $\mathrm{QKD}^{19}$ protocols based on polarization encoding.

Here, we review the practical approaches for production of nitride QD SPSs. We consider two groups of approaches, divided by the strategy used for QD fabrication. First, we will address bottom-up approaches, which exploit self-assembled QDs, such as those formed by SK growth. Thereafter, we will address site-controlled QDs, where lithographic techniques are used to achieve QD formation - for example the growth of nanorods through lithographically-defined apertures, incorporating insertions which act as QDs. We describe the advantages and disadvantages of these approaches, common challenges which arise and possible solutions to them.

Self-assembled QDs - In most semiconductor systems, including the conventional III-Vs, the most common routes to the fabrication of SPSs exploit QD self-assembly in the SK growth mode. SK growth is successfully applied to nitride QD formation in molecular beam epitaxy (MBE). However, metal organic vapour phase epitaxy (MOVPE) is more widespread, particularly in industry. SK growth of QDs is feasible using MOVPE for GaN QDs on $\mathrm{AlN}^{20}$, but is challenging for the growth of InGaN QDs on GaN and a plethora of alternative mechanisms have been investigated ${ }^{21,22,23,24}$, only a minority of which ${ }^{25,26}$ have proved applicable to SPSs. Here, we focus on QD growth routes which have been demonstrated to achieve single photon emission using the Hanbury-BrownTwiss (HBT) experiment.
The earliest example of a nitride SPS was presented by Kako et $a l .{ }^{27}$ in 2006 . GaN QDs emitting at $\sim 350 \mathrm{~nm}$ were grown in the SK mode on AlN by MOVPE. The emission from the QDs was examined using the HBT setup ${ }^{28}$, which measures the second order correlation function $g^{(2)}(\tau)$ of the emission, describing the joint probability of detecting the arrival of a photon at time $t$ and of another photon at time $t+$ $\tau$. For an SPS, $g^{(2)}(\tau)$ exhibits an "antibunching" dip, ideally to 0 , at $\tau=0$. For the GaN QDs examined by Kako et al., $g^{(2)}(0)=0.42$, and this relatively high value was attributed to underlying background emission from sources other than the single QD under study. More impressively, a measurable antibunching $\operatorname{dip}\left(g^{(2)}(0)=0.53\right)$ was retained at $200 \mathrm{~K}$. Such temperature stability is difficult to achieve in the conventional III-Vs and was attributed to a high barrier to carrier escape from the QD resulting from the very wide bandgap AlN barriers. These early results illustrated the potential of the nitrides in realising practical SPSs at accessible temperatures.

This work represented a great achievement in UV emission, but failed to access the blue-green wavelength range desired for easy single photon detection. For visible emission, InGaN QDs in a GaN matrix were explored - avoiding the use of an AlN matrix which, whilst helpful in achieving temperature stability, may cause problems in the development of electrically pumped SPS since its very wide bandgap makes it difficult to dope. The first InGaN/GaN SPS $^{25}$ was grown using MOVPE exploiting a variant of droplet epitaxy to achieve QD formation ${ }^{22}$. When combined with two photon optical excitation, bright QD luminescence could be identified with very little background, facilitating HBT experiments on InGaN QDs grown atop an AlN/GaN distributed Bragg reflector (DBR) to aid photon extraction. An SPS emitting at $435 \mathrm{~nm}$ was thus demonstrated, with a $g^{(2)}(0)$ value very close to zero (Fig. 2) ${ }^{25}$. A further MOVPE-grown InGaN SPS at a similar wavelength was later presented by Kremling et al. ${ }^{26}$ who exploited a novel growth mechanism involving phase separation $^{29}$, and thus demonstrated single photon emission from InGaN QDs at temperatures up to $50 \mathrm{~K}$.

Whilst early nitride SPSs exploited MOVPE, impressive results have recently been achieved in MBE: An MBE-grown QD LED has demonstrated electrically-pumped single photon emission at $280 \mathrm{~K}^{30}$. Although electroluminescence (EL) from single MOVPE-grown InGaN QDs had been seen before ${ }^{31}$, those devices were insufficiently stable for HBT assessment. The MBE device fabricated by Deshpande et al. ${ }^{30}$ exhibits single photon EL at both $15 \mathrm{~K}$ and $280 \mathrm{~K}$, a particularly impressive feat given the challenges of obtaining p-type conductivity at low temperature. (The ionisation energy of the relevant acceptor ( $\mathrm{Mg}$ ) is large). Hole conduction may actually occur via an impurity band in this case ${ }^{32}$. The LED emits at $590 \mathrm{~nm}$ - an unusually long wavelength for InGaNbased devices - because of the relatively high indium content of the QDs used (ca. 40\%), so that there is a large band offset between $\mathrm{InGaN}$ and $\mathrm{GaN}$ aiding high temperature operation. To reach a similar level of temperature stability for a blue emitter, which would require an indium content of ca. $20 \%$, 

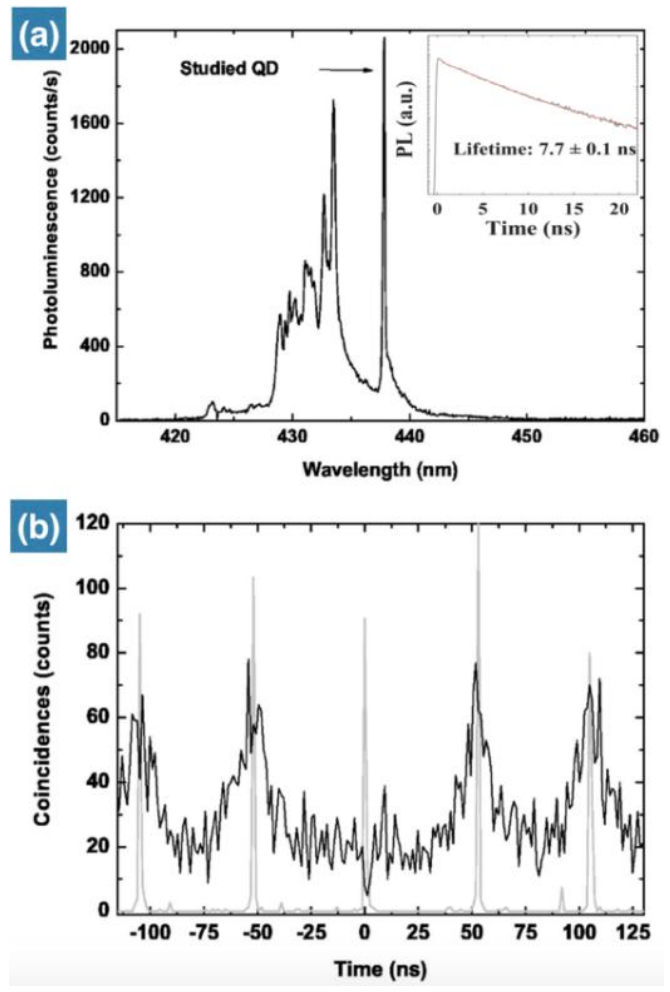

Fig. 2: (a) $\mu \mathrm{PL}$ spectrum of an InGaN QD array atop a DBR recorded at $4.2 \mathrm{~K}$. (b) Photon correlation spectrum (black trace) of the QD shown in (a), showing the anti-bunching dip. The measured correlation spectrum of the laser light used to excite the QD is shown for reference (grey trace). Figure reproduced with permission from Reference [25] (C) 2007, AIP Publishing LLC.

may require $\mathrm{InGaN}$ to be combined with a material with a larger bandgap than $\mathrm{GaN}$, in order to increase the band offsets.

InGaN QDs with wider AlGaN barriers can be grown by MOVPE $^{33}$ on planar surfaces but, for a successful InGaN/AlGaN SPS, we must discuss a very different QD self assembly route - the growth of self assembled nanowires (NWs), with axial insertions of a lower bandgap semiconductor forming the QDs. Deshpande et al. ${ }^{34}$ exploited a self-catalysed vapour-liquid-solid (VLS) growth mechanism in $\mathrm{MBE}$, producing $\mathrm{AlGaN}$ NWs with InGaN insertions (Fig. 3 ), which acted as QDs, exhibiting optically pumped single photon emission at $450 \mathrm{~nm}$ at up to $200 \mathrm{~K}$. As with the early work using MOVPE-grown GaN QDs, the value of $g^{(2)}(0)$, particularly at $200 \mathrm{~K}$, was quite high $(0.54$ in the raw HBT data), again partly due to the difficulty of isolating the QD signal from the background. This issue arises across the field of nitride SPSs in spite of the use of many different fabrication routes. The MBE growth of self-assembled NWs has also produced a NW LED consisting of an InGaN insertion in a $\mathrm{GaN} \mathrm{NW}$, with n-doped and p-doped $\mathrm{GaN}$ grown before and after the insertion. This LED exhibited single photon EL at ca. $435 \mathrm{~nm}$ at up to $200 \mathrm{~K}^{35}$. Both the electrically and optically pumped devices emitted light
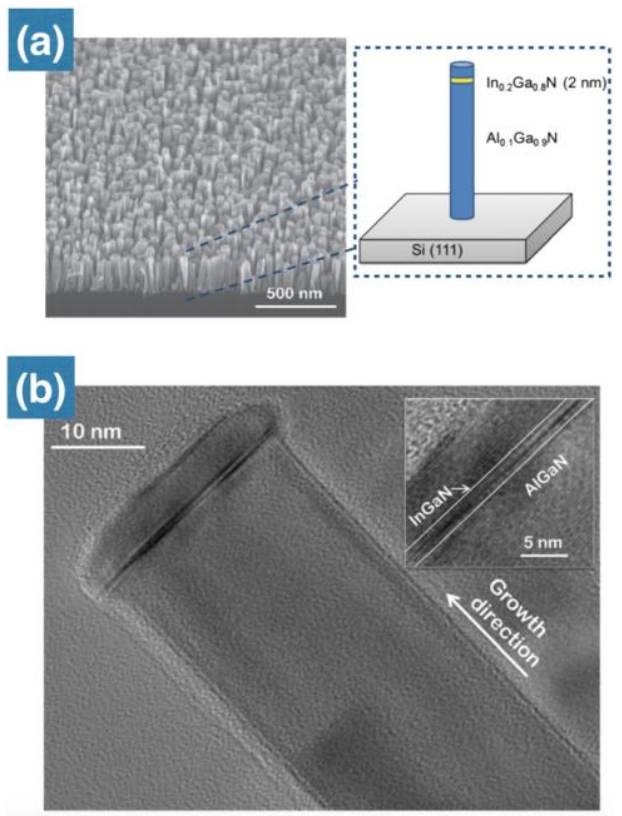

Fig. 3: (a) Scanning electron microscopy (SEM) image of NWs grown by MBE with a schematic illustration of an InGaN QD in an AlGaN NW; (b) transmission electron microscopy (TEM) image of one NW with a high resolution image of the InGaN QD inset. Figure reproduced with permission from reference [34] (C) 2013, AIP Publishing LLC.

linearly polarised parallel to the NW axis, with a degree of linear polarisation (DOLP) of $\sim 70 \%$. However, a NW LED needs specialised processing, but the earlier planar device required only minor adaptations of a standard LED process.

Site-controlled QDs - Self-assembled QDs are cheap to fabricate since no patterning steps are required. However, QD locations are randomly distributed and QD properties vary. More uniform QDs at fixed positions can be achieved using lithographic means and recently such site-controlled nitride QDs have been successfully used in SPSs. Two basic approaches have been applied. The first, an entirely top-down strategy, involves patterning a planar QW using electron beam lithography, and then etching pillars a few tens of nanometers in diameter, forming QDs as insertions along the axis of an etched $\mathrm{NW}^{36}$. This approach met with little success in the arsenides due to the detrimental impact of surface states at the etched sidewalls ${ }^{37}$. However, the nitrides have surface recombination velocities two to three orders of magnitude lower than the arsenides, rendering the impact of surface states less severe ${ }^{36}$. The second approach combines some of the advantages of self-assembly with site-control and involves deposition of a masking material on $\mathrm{GaN}$ and growth of nanostructures through holes in the mask. QDs may be formed as insertions in a site-controlled NW (Fig. 4(a) and (b)), or at the apex of a site-controlled pyramid (Fig. 4(c)). Whilst the top down etching approach has been successfully applied by Teng et $a l^{38}$ to form elliptical InGaN QDs, and hence an SPS with deterministically controlled polarisation, the majority of 
site-controlled nanostructure SPSs exploit growth through a mask, and we will explore this approach in more detail.

Holmes et al. ${ }^{39}$ grew GaN NWs using MOVPE exploiting $25 \mathrm{~nm}$ apertures defined by e-beam lithography in a $\mathrm{SiO}_{2}$ mask. The initial GaN NWs were coated with AlGaN to form core-shell structures which were overgrown with a thin GaN layer and capped with more AlGaN. A GaN QD is formed at the sharp NW apex, which TEM (Fig. 4(b)) revealed to be smaller than typical SK GaN/AIN QDs. QD emission is thus observed further into the UV, achieving optically pumped single photon emission at ca. $285 \mathrm{~nm}$. The small QD size results in a reduced internal electric field, improving the electron-hole wavefunction overlap and reducing the exciton lifetime, allowing higher repeat rates to be achieved. The small size of the QD may also contribute to the good performance of this SPS up to room temperature $\left(g^{(2)}(0)=\right.$ 0.33 at $300 \mathrm{~K}$ for the raw data) since the energy levels will be more widely spaced than in larger structures, reducing the probability of carrier excitation into higher lying states. However, the large band offset between QD and barrier is again probably the key factor. Despite the low density of nanostructures arising from the site controlled approach, there was still a significant background signal affecting $g^{(2)}(0)$, presumably arising in part from sidewall QWs on the NW.

Chernysheva et $a l^{40}$ also produced an SPS using sitecontrolled GaN NWs, with an InGaN QD formed at the apex of a pyramid at the end of the NW. MBE was used in this case rather than MOVPE, showing that this approach is tractable in both major growth techniques. Furthermore, nanosphere lithography was used, avoiding slow and time-consuming electron beam lithography, although at the cost of reduced positional control. However, Jemsson et al. ${ }^{41}$ were able to produce an SPS based on the growth of site controlled GaN micropyramids with InGaN QDs at their apices, avoiding nanolithography entirely. The mask was a $\mathrm{SiN}_{\mathrm{x}}$ layer with circular openings of diameter ${ }^{42} 2.5 \mu \mathrm{m}$ defined by standard photo-lithography. Appropriate growth conditions were used to form inclined side facets which meet at a sharp apex where the QD is grown. Initially, $g^{(2)}(0)$ values were conspicuously high $\left(g^{(2)}(0)=0.8\right.$ in the raw data) due to contamination of the QD signal with background emission from QWs on the pyramid sidewalls ${ }^{43}$. However, an additional processing step applying a metal layer across the whole sample which was then etched away from the apices of the pyramids (without additional lithography) reduced the background substantially, allowing respectable values of $g^{(2)}(0)$ to be achieved for QDs emitting light with a DOLP of ca. $85 \%$ and showing some evidence for anti-bunching at temperatures up to $80 \mathrm{~K}^{41}$.

Gong et al. ${ }^{44}$ performed similar fabrication, but deposited $40 \mathrm{~nm}$ of silver on top of the pyramids to allowed coupling of the QD emission to a plasmon mode, enhancing the spontaneous emission rate from the QD (at $500 \mathrm{~nm}$ ) by a factor of more than 20. This work represents a rare attempt to integrate site-controlled nitride QDs with other device components. QD LEDs and other devices are generally fabricated using self-assembled QDs due to the difficulty of
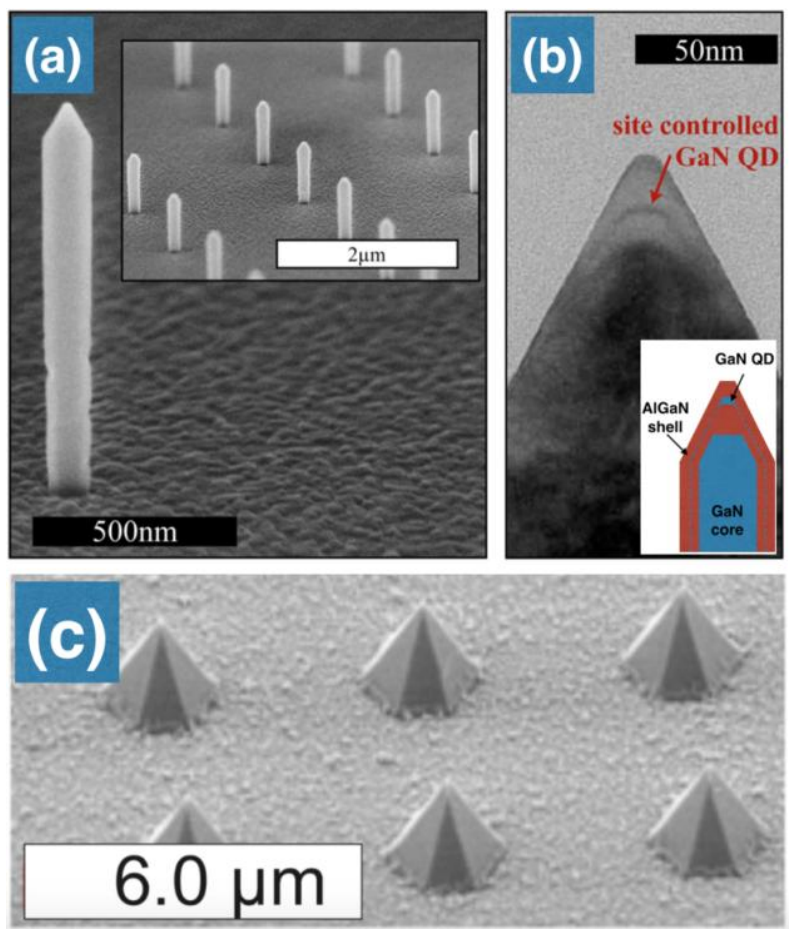

Fig. 4: Images of site-controlled nitride QDs. (a) SEM images showing NWs grown on a patterned $\mathrm{SiO}_{2}$ substrate by MOVPE. (b) TEM image of a single GaN QD near the tip of an AlGaN NW, illustrated schematically in the inset. (c) SEM image of site-controlled $\mathrm{GaN} / \mathrm{InGaN} / \mathrm{GaN}$ pyramids, again with a QD near the apex. Reprinted with permission from Reference [39] (C) 2014, American Chemical Society (Parts a, b) and from reference [45] () 2012, IOP Publishing (Part c).

achieving other device processing steps in the site-controlled case around the large three-dimensional structures (pyramids or NWs) used to template the QD growth. Considering potential future devices, integrating QDs into high quality factor three-dimensional microcavities for example, then processing of samples based on planar self-assembly will again be simpler than using site-controlled QDs, but the lack of spatial control will in this case make it difficult to spatially align the QD locations to overlap with the cavity mode.

In addressing integration of QDs into advanced devices, we can take inspiration from progress in the better-developed III-arsenides where, although a number of innovative attempts ${ }^{46,47,48}$ have been made to exploit the geometry of sitecontrolled nanorods in the development of efficient and/or highly integrated SPSs, the most significant progress in integrating QDs into structures such as microcavities has involved self-assembled QDs. QD-cavity coupling has been achieved using self-assembled QDs in several geometries (microdisks ${ }^{49}$, micropillars ${ }^{50}$ and photonic crystals ${ }^{51}$ ), and all optical methods to achieve spatial overlap of the QD with the cavity mode ${ }^{52}$ have mitigated the impact of the random positioning of self-assembled structures. Given the increasing maturity of cavity fabrication technologies in the IIINitrides $^{53,54,55,56,57,58}$ (Fig. 5), this approach may be ripe 

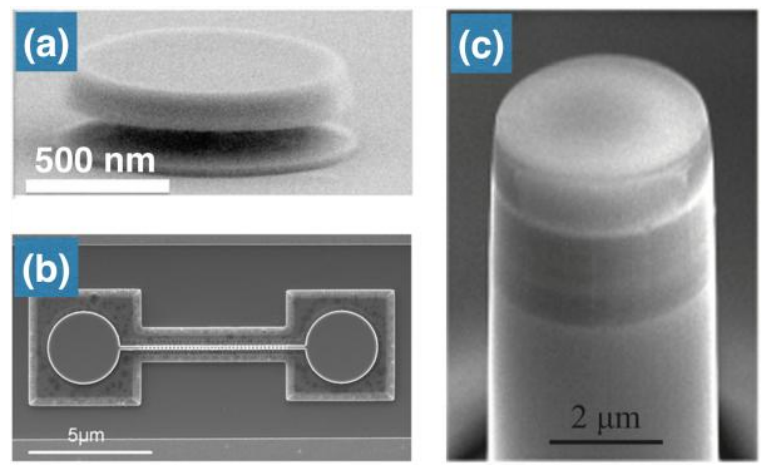

Fig. 5: SEM images of various nitride microcavities: (a) GaN microdisk. (b) Photonic crystal nanobeam. (c) Micro-pillar. Figure reproduced with permission from reference [55] (C) 2014, PNAS (a), reference [58] @ 2015, AIP Publishing LLC (b), reference [54] (C) 2012, AIP Publishing LLC (c).

for investigation in GaN. Nonetheless, device development in the arsenides increasingly exploits site-controlled QDs, but not using the large three-dimensional structures such as pyramids and NWs which we discussed above. Instead, nanoscale patterns, such as holes ${ }^{59}$ are being used to control nucleation of QDs formed in the SK growth mode ${ }^{60}$ (Fig. 6), allowing simultaneous precise control of the QD position and integration with other epitaxial structures such as DBRs ${ }^{61}$. This type of templating could be explored to achieve deterministic QD-cavity coupling in the nitrides.

Challenges - Throughout our discussion of nitride SPSs, background signals which contaminate the single photon stream have been noted. In self-assembled planar epitaxy, this is due to other QDs or surrounding QWs (e.g. the wetting layer for SK QDs). The use of sparse, lithographically-defined QD nucleation sites (as in Fig. 6) could reduce this background emission. When NWs or micropyramids are used to grow QDs, sidewall QWs contribute to the background even for isolated nanostructures and additional processing steps, as used by Jemsson et al. ${ }^{43}$ may be necessary.

Another common issue is spectral diffusion: a variation in the peak emission wavelength of a QD on a few second timescale. For coupled QD-cavity systems, this will lead to loss of resonance between QD and cavity. It occurs in both the planar $^{62}$ and the $\mathrm{NW}^{63}$ geometry and is exacerbated by the huge internal electric fields in QDs grown on the polar cplane. Changes in the local electric field due to charge trapping at extended defects ${ }^{64}$ (or in the case of NWs possibly surface traps) modify the QD internal field, and hence the related band-bending, shifting the transition energies. Spectral diffusion on the few second timescale can be mitigated by reducing the trap density ${ }^{64}$, but there is also a fast-timescale component, thought not to be linked to extended defects or surfaces, which broadens the observed QD emission, and which is more difficult to address. The magnitude of the spectral diffusion increases in proportion to the internal field ${ }^{65}$; hence reducing this field could mitigate the problem.

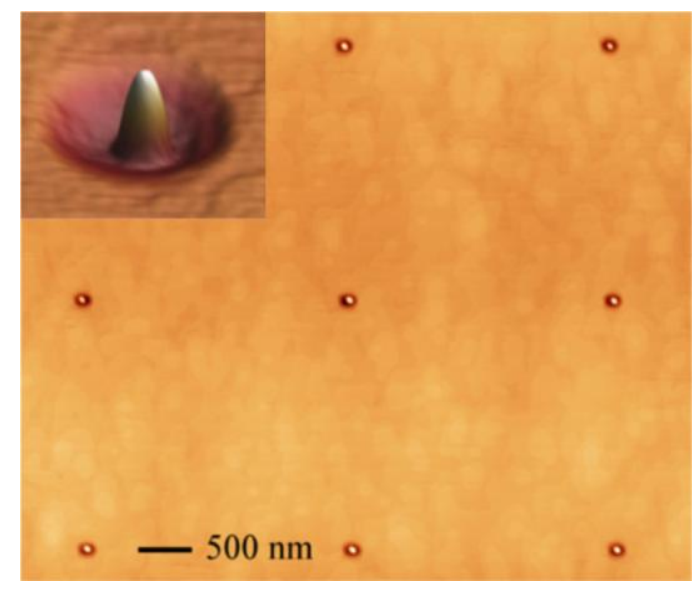

Fig. 6: (a) AFM image of an array of InAs site-controlled QDs in pits in a GaAs substrate, with (inset) a 3D render of a single QD at higher magnification. Figure reproduced with permission from reference [59] () 2013, IOP Publishing.

To reduce internal fields, QDs can be grown on a nonpolar plane. This greatly shortens the exciton lifetimes ${ }^{66,67}$, a signature of the smaller field, and yields very narrow QD emission linewidths ${ }^{67}$ indicating reduced short-timescale spectral diffusion. Whilst an SPS in this orientation has not yet been demonstrated, these QDs have promising properties. The short lifetimes will allow high repetition rates and reduced time-jitter of emission, and valence-band mixing effects result in a DOLP of $100 \%$ for a large proportion of the $\mathrm{QDs}^{17}$, with the polarisation direction aligned along a specific crystallographic axis. Impressively for an $\mathrm{InGaN} / \mathrm{GaN}$ structure, these QDs do not exhibit linewidth broadening ${ }^{68}$ up to $140 \mathrm{~K}$, and may thus be candidates for a stable blue SPS operating at easily accessible temperatures.

Eliminating spectral diffusion is vital if nitride SPSs are to be used in LOQC or other applications in quantum information processing where photon indistinguishability is a prerequisite. Furthermore, indistinguishable photons must also be in exactly the same mode ${ }^{28}$. Photons emitted from arsenide QDs have been proved to be indistinguishable using a HongOu-Mandel setup ${ }^{69}$ but this hurdle must be addressed in the nitrides, if they are to be applied in quantum computation.

Conclusions - Overall, given the inherent challenges presented by nitrides, including very high defect densities and internal electric fields, progress on nitride quantum light sources has been surprisingly swift. The largest opportunities they present are the broad range of wavelengths they can access and the potential for efficient, stable sources operating at accessible temperatures. However, spectral diffusion and other ubiquitous challenges must be overcome.

Throughout this review, we have drawn inspiration from the more mature arsenides, to suggest routes forwards for the nitrides. Now instead we ask what inspiration the conventional III-V community might draw from the nitrides? If large band offsets in the nitrides are key to achieving good temperature stability, what arsenide- or phosphide-based 
materials combination might achieve such large band offsets in the infra-red communications window? One route forward might be to combine the nitrides with more conventional III$\mathrm{Vs}$, considering what bandgaps and band offsets can be achieved using the so-called "dilute nitrides", e.g. Ga(In)NAs. Novel methods for SPS development in these materials are emerging ${ }^{70}$. Progress on nitride quantum light sources shows that other newer, less perfect or poorly understood semiconductors are worth exploring in this context.

We acknowledge funding from the EPSRC (EP/M011682/1).

\section{REFERENCES}

${ }^{1}$ SHIELDS A. J., Nature Photon., 1 (2007) 215.

${ }^{2}$ Gisin N., Ribordy G., TITTEL W. and ZBinden H., Rev. Mod Physics, 74 (2001) 145.

${ }^{3}$ Knill E., Laflamme R. and Milburn, G. J., Nature, 409 (2001) 46.

${ }^{4}$ Lounis B and Orrit M., Rep. Prog. Phys., 68 (2005) 1129.

5 Michler P., KirAZ A., Becher C., SchOenfeld W. V., Petroff P. M., Zhang L., Hu E. and Imamoglu A., Science, 290 (2000) 2282.

6 Yuan Z., Kardynal B. E., Stevenson R. M., ShieldS A. J., Lobo C. J., CoOPer K., BeAtTIE N. S., Ritchie, D. A. and PEPPER M., Science, 295 (2002) 102.

7 TAKeMOto K., TAKatsu M., Hirose S., YoKoyama N., SAKUMA Y., USUKI T., MIYAZAWA T. and AraKaWa Y., J. Appl. Phys., 101 (2007) 081720.

${ }^{8}$ Santori C., Fattal D., Vuckovic J., SOlOMON G. S., and Yамамото Y., Nature, 419 (2002) 594.

9 Stevenson R. M., Young R. J., AtKinson P., CoOper K., Ritchie D. A. and ShIElds A. J., Nature, 439 (2006) 179.

${ }^{10}$ SAlter C. L., Stevenson R. M., FARrer I., Nicoll C. A., Ritchie D. A. and ShIEldS A. J., Nature, 465 (2010) 594.

${ }^{11}$ Pelton M., SAntori C, Vuckovic J, Zhang B. Y., Solomon G. S., Plant J. and Yamamoto Y., Phys. Rev. Lett., 89 (2002), 233602.

12 Kiraz A., Michler P., Becher C., Gayral B., IMAMOĞLU A., Zhang L., Hu E., SCHOENFEld W. V. and Petroff P. M., Appl. Phys. Lett., 78 (2001) 3932.

${ }^{13}$ ThON S. M., RAKHER M T., KIM H., GUdAT J., IRVINE W. T. M., Petroff P. M. and BouwMeEster D., Appl. Phys. Lett., 94 (2009) 111115.

14 Prtljaga N., Coles R. J., O'Hara J., Royall B., Clarke E., FoX A. M. and M. S. SkOlniCK, Appl. Phys. Lett., 104 (2014) 231107.

15 Aichele T., Scholz M. and Benson O., Proc. IEEE, 95 (2007) 1791.
16 Sebald K., Michler P., Passow T., Hommel D., BACHER G. and Forchel A., Appl. Phys. Lett., 81 (2002) 2920.

${ }^{17}$ JARJOUR A. F., OLIVER R. A., TAHRAOUI A., KAPPERS M. J., HumphreYs C. J. and TAYlOR R. A., Phys. Rev. Lett. 99 (2007) 197403.

${ }^{18}$ ReID B., P. L., Kocher C., ZHU T., OEHLER F., CHAN C. C. S., Oliver R. A. and TAYlor R. A., Appl. Phys. Lett. 106 (2015) 171108.

${ }^{19}$ WAKs E., InOUE K. and YAMAMOto Y., Nature, 420 (2002) 762

${ }^{20}$ MiYamura M., TACHIBANA K. and ARAKAWA Y., Appl. Phys. Lett., 80 (2002) 3937.

${ }^{21}$ Tachibana K., Someya T. and Arakawa Y., Appl. Phys. Lett., 74 (1999) 383.

22 Oliver R. A., Briggs G. A. D., Kappers M. J., HuMPHREYS C. J., YASIN S., RICE J. H., SMITH J. D. and TAYlor R. A., Appl. Phys. Lett., 83 (2003) 755.

23 YAMAguchi T., DENNEMARCK J., TESSAREK C., SEBALD K., GangOPADHYAy S., FAlta J., GutOWSKI J., Figge S. and Hommel D., Phys. Status Solidi $C, 4$ (2007) 2407.

${ }^{24}$ WANG Q., WANG T., BAI J., CUllis A. G., PARBROOK P. J. and F. Ranalli, J. Appl. Phys., 103 (2008) 123522.

25 Jarjour A. F., TAYlor R. A., Oliver R. A., KAPPERS M. J., Humphreys C. J. and TAHRAOUI A., Appl. Phys. Lett., 91, (2007) 52101.

${ }^{26}$ Kremling S., TessareK C., Dartsch H., FigGe S., HöFling S., Worschech L., KRUSE C., HoMmel D. and ForChEl A., Appl. Phys. Lett., 100 (2012) 061115.

${ }^{27}$ KaKo S., SANTORI C., Hoshino K., GÖtZINGER S., YAMAMOTO Y. and ARAKAWA Y., Nat. Mater., 5 (2006) 887.

28 BuCKLEY S., RIVOIRE K. and VuĈKOVIĆ J., Rep. Prog. Phys. 75 (2012) 126503.

${ }^{29}$ Tessarek C., Figge S., Aschenbrenner T., Bley S., Rosenauer A., Seyfried M., Kalden J., Sebald K., Gutowski J. and Hommel D., Phys. Rev. B, 83 (2011) 115316

30 DEShPANDE S., Frost T., HAZARI A. and Bhattacharya P., Appl. Phys. Lett. 105 (2014) 141109.

31 JARJOUR A. F., TAYlor R. A., Oliver R. A., KAPPERS A. J., HUMPHREYS C. J. and TAHRAOUI A., Appl. Phys. Lett. 93 (2008) 233103.

${ }^{32}$ Götz W., Johnson N. M., WALKer J., Bour D. P. and Street R. A., Appl. Phys. Lett. 68 (1996) 667.

${ }^{33}$ Oliver R. A., El-Ella H. A. R., COllins D. P., ReID B., ZHANG Y., CHRISTIE F., KAPPERS M. J. and TAYLOR R. A., Mat. Sci. Eng. B 178 (2013) 1390.

${ }^{34}$ DeshPande S., DAS A. and BhatTaCharya P., Appl. Phys. Lett, 102 (2013) 161114.

35 Deshpande S., Heo J, Das A. and Bhattacharya P., Nat. Commun., 4 (2013) 1675. 
${ }^{36}$ Zhang L., Teng C.-H., Hill T. A., LeE L.-K.,. KU P.C. and Deng H., Appl. Phys. Lett., 103 (2013)192114.

37 ForChel A., STEFFEN R., KoCH T., Michel M., Albrecht M. and Reinecke T. L., Rep. Prog. Phys. 75 (2012) 126503. Sci. Technol., 11 (1996) 1529.

38 Teng C.-H., Zhang L., Hill T. A., Demory B., Deng H. and KU P.-C., Appl. Phys. Lett. 107 (2015) 191105.

39 Holmes M. J., ChOI K., KaKo S., ARITA M. and ARAKAWA Y., Nano Lett., 14 (2014) 982.

${ }^{40}$ ChernysheVA E., GaČEVIĆ Ž, GarCía-LePetit N., VAN DER MEUlen H. P., MÜLler M., Bertram F., Veit P., TORRes-PARdo A., GonzÁlez CAlbet J. M., Christen J., Calleja E., Calleja J. M. and Lazić S., EPL, 111 (2015) 24001.

41 Jemsson T., MachHadani H., Holtz P.-O. and KARLSSON K. F., Nanotechnology, 26 (2015) 065702.

42 HSU C.-W., Lundskog A., KARLSSON K. F., Forsberg U., JANZÉN E. and HoltZ P. O., Nano Lett. 11 (2011) 2415.

${ }^{43}$ JemsSon T., MachHadani H., Karlsson K. F., HSU C.-W. and Holtz P.-O., Appl. Phys. Lett. 105 (2014) 081901

${ }^{44}$ GoNG S.-H., KIM J.-H., Ko Y.-H., RodRIGUEZ C., SHIN J., LEE Y.-H., DANG L. S., ZHANG X. and CHO Y.H., PNAS, 112 (2015) 5280.

${ }^{45}$ Lundskog A., Palisaitis J., Hsu C. W., ERIKSSON M., Karlsson K. F., Hultman L., Persson P. O. A., FORSBERG U., HOLTZ P. O. and JANZÉN E., Nanotechnology 23 (2012) 305708.

${ }^{46}$ Claudon J., Bleuse J., Malik N. S., Bazin M., JAFFrennou P., GREGERSEN N., SAUVAN C., LALANNE P. and GERARD J. M., Nature Photon., 4 (2010) 174.

47 Watson D. C., Martinez R.V., Fontana Y., RUSSO-AVERCHI E., HeISS M. , FONTCUBERTA I Morral A., Whitesides G. M. and LONCAR M., Nano Lett., 14 (2014) 524.

${ }^{48}$ ZHA G. W., Shang X. J., NI H. Q., YU Y., XU J. X., WeI S.H., MA B., ZhANG L. C. and NIU Z. C., Nanotechnology 26 (2015) 385706.

${ }^{49}$ Peter E., Senellart P., MARtrou D., Lemaitre A., Hours. J., Gerard J.M. and Bloch J., Phys. Rev. Lett. 95 (2005) 067401.

50 SeK G, Hofmann C, Reithmaier J. P., LOFFler A, REITZENSTEIN S., KAMP M., KELDYSH L. V., KULAKOVSKII V. D., REINECKE T. L. and FORCHEL A., Physica E 32 (2006) 471.

${ }^{51}$ Yoshie T., SCHERER A., Hendrickson J., KHITROVA G., GibBs H. M., RupPer G., Ell C., SHCHEKIN O.B. and DEPPE D.G. Nature 432 (2004) 200.

${ }^{52}$ THON S. M., RAKHER M. T., KIM H., GUdAT J., IRVINE W. T. M., Petroff P. M. and BouwMeEster D., Appl. Phys. Lett. 94 (2009) 111115.
53 Tamboli A. C., Haberer E. D., Sharma R., LeE K. H., NAKAMURA S. and HU E. L., Nature Photon., 1 (2007) 61.

${ }^{54}$ El-Ella H. A. R., Collins D. P., KapPers M. J., TAYlor R. A. and Oliver R. A., J. Appl. Phys. 112 (2012) 113516.

${ }^{55}$ Woolf A., Puchtler T., Aharonovich I., Zhu T., NiU N., Wang D., Oliver R. and Hu E.L., Proc. Natl. Acad. Sci. USA 111 (2014) 14042.

56 Trivino N. V., Butté R., CARlin J.-F. and GRANDJEAN N., Nano Lett., 15 (2015) 1259.

57 TAO R., ARITA M., KAKO S., KAMIDE K. and AraKaWA Y., Appl. Phys. Lett. 107 (2015) 101102.

58 NiU N., WoOlF A., Wang D., ZHU T., QUAN Q., Oliver R. A. and Hu E. L., Appl. Phys. Lett. 106 (2015) 231104.

59 TOMmila J., SCHramm A., HAKKarainen T. V., DUMITRESCU M. and GUINA M. Nanotechnology 24 (2013) 235204.

${ }^{60}$ Chang H.-S., Hsu C.-M., YANG M.-H., HsIEH T.-P., CHYI J.-I. and HsU T.-M., Phys. Status Solidi (c) 5 (2008) 2713.

${ }^{61}$ Minghui Y., QiXIAnQ S., SHIJUn L. and JingSBEng. L., Optoelectron. Adv. Mat. 9 (2015) 36.

${ }^{62}$ Rice J. H., RoBinson J. W., JARJOUR A., TAYlOR R. A., Oliver R. A., Briggs G. A. D., KAPPERS M. J. and Humphreys C. J., Appl. Phys. Lett. 84 (2004) 4110.

63 Holmes M., KAKO S., ChOI K., ARITA M. and Arakawa Y., Phys. Rev. B 92 (2015) 115447.

${ }^{64}$ ReID B. P. L., ZHU T., PUCHTLER T. J., FletChER L.

J., ChAN C. C. S., Oliver R. A. and TAYlOR R. A., Jpn. J. Appl. Phys. 52 (2013) 08JE01.

${ }^{65}$ Hönig G., Rodt S., Callsen G., Ostapenko I. A., Kure T., Schliwa A., Kindel C., Bimberg D. and Hoffmann A., Phys. Rev. B 88 (2013) 045309.

${ }^{66}$ Zhu T., Oehler F., ReID B. P. L., EMERY R. M., TAYlor R. A., KapPers M. J. and Oliver R. A., Appl. Phys. Lett. 102 (2013) 251905.

${ }^{67}$ GrifFITHS J. T., ZHU T., OEHLER F., EMERY R. M., FU W. Y., ReID B. P. L., TAYlOR R. A., KAPPERS M. J., Humphreys C. J. and Oliver R. A., APL Mater. 2 (2014) 126101.

${ }^{68}$ ReID B. P. L., Zhu T., Chan C. C. S., Kocher C., OEHLER F., EMERY R., KAPPERS M. J., OLIVER R. A. and TAYlor R. A., Phys. Status Solidi C 11 (2014) 702.

${ }^{69}$ Hong C. K., OU Z. Y. and Mandel L., Phys. Rev. Lett. 59 (1987) 2044.

${ }^{70}$ Birindelli S., Felici M., Wildmann J.S., Polimeni A., CAPIZZI M., Gerardino A., Rubini S., Martelli F., Rastelli A. and Trotta R., Nano. Lett. 14 (2014) 1275. 